\title{
The Effect of Aspirin on Survivin and COX-2 Expression and Their Correlation in Aberrant Crypt Foci
}

\author{
Maggie M. Ramzy*, Soha A. Abdelwahab** \\ Biochemistry * \& Histology Departments** \\ Faculty of Medicine, Minia University
}

\begin{abstract}
Non steroidal anti-inflammatory drugs (NSAID) such as aspirin have chemopreventive activity against colorectal tumors. Although the molecular mechanism has not been fully established, it is thought to involve COX-mediated carcinogen activation, cell proliferation, apoptosis and immune surveillance. In the present study, the effect of aspirin on the expression of survivin and COX-2 and their possible correlation in induced colorectal carcinoma were investigated. We used 1, 2 dimethylhydrazine (DMH) for induction of aberrant crypt foci (ACF) that contribute to the stepwise progression to colorectal cancer. The rats were divided into 3 groups; control group, DMH group and DMH with aspirin group. The expression of survivin and COX-2 was investigated through IHC and immunoblot and the correlation in both DMH-induced lesions and after aspirin treatment was evaluated. It was found that aspirin has the ability to reduce the incidence of the ACF when it was given as a chemopreventive and it was found that both survivin and COX-2 are overexpressed in ACF compared to normal group. They seem to be early events in the occurrence of colorectal carcinoma. In the evaluation to the effect of aspirin it was found that aspirin significantly causes down-regulation of both survivin and COX-2 $(P=0.0001)$. Furthermore, we found survivin and COX-2 to be positively correlated in ACF lesion and after aspirin treatment ( $r=0.816$ and $r=0.742)$ respectively. All of these findings suggested that targeted therapies against survivin and $C O X-2$ may be valuable in chemoprevention of colorectal carcinoma.
\end{abstract}

Key words: Aspirin, aberrant crypt foci, survivin, cyclooxygenase-2

\section{INTRODUCTION}

The development of colon cancer is a multistep process involving inactivation and ectopic activation of different genes, and a morphologic progression from superficial adenomatous polyps to frank, invasive adenocarcinoma $^{[1]}$. Aberrant crypt foci are generally accepted as precancerous lesions in regard to histopathological characteristics, biochemical and immunohistochemical alterations, as well as genetic and epigenetic alterations ${ }^{[2]}$.

Aspirin reduces risk of colorectal neoplasia in randomized trials and inhibits tumor growth and metastases in animal models ${ }^{[3]}$. It is known to act directly by suppressing the cyclooxygenase enzymes (COX-1 and COX-2), which are the rate-limiting enzyme catalyzing the biosynthesis of prostaglandins ${ }^{[4]}$. Several lines of 
evidence have demonstrated that COX-2 and its product, $\mathrm{PGE}_{2}$, play an important role in the promotion of intestinal tumorigenesis ${ }^{[5]}$.

The pro-tumorigenic effect of COX-2 has been attributed to its ability to enhance cell proliferation and angiogenesis, while inhibiting cell differentiation and apoptosis ${ }^{[5]}$, thus, COX-2 is an attractive target in cancer therapy, and understanding the mechanisms involved in controlling its expression are of great interest ${ }^{[6]}$.

Survivin gene is a recently characterized gene located on chromosome $17 \mathrm{q} 25$, and a member of the inhibitor of apoptosis protein (IAP) family, whose members inhibit apoptosis through a pathway different from that involving the bcl-2 family ${ }^{[7]}$. The IAP family of proteins is characterized by the presence of one to three domains, rendering antiapoptotic activity by binding to caspases ${ }^{[8]}$. The effector caspases-3 and 7 and the initiator caspases- 9 are among the caspases that are directly inhibited by human IAP family members (IAP-1, IAP-2, XIAP, and survivin) ${ }^{[4] .}$

Survivin is mainly localized in the cytoplasm of neoplastic cells, although some tumors may exhibit nuclear expression ${ }^{[9]}$. Survivin expression has been extensively evaluated in cancer $^{[10]}$ and its expression in normal tissue is developmentally regulated and has been reported to be low in most terminally differentiated tissues. The aberrant high expression of survivin in cancer cells, with little expression in most normal tissues, makes survivin an attractive anticancer target [11]. Also, it was demonstrated that down- regulation of expression of antiapoptotic genes such as survivin is responsible for the augmentation of tumor necrosis factor-related apoptosis-inducing ligand (TRAIL) induced apoptotic death ${ }^{[4]}$.

In the current study we aimed to examine the expression of both survivin and COX-2 in early stages of colorectal carcinoma and the effect of acetylsalicylic acid (ASA) on their expression, also if there is any correlation between these two proteins in colon tumorigenesis.

\section{MATERIAL \& METHODS}

1- Animal study:

Thirty male albino rats at 2 months of age weighing 200-250 g. were used for the study. Rats were divided into 3 groups each of 10 rats. Rats were housed in animal cages with food and water ad libitum with standard laboratory conditions.
2- Animal treatment and experimental design:

Group A received a weekly dose of $0.5 \mathrm{ml}$ of saline subcutaneously for 8 weeks as a negative control.

Group B received a weekly subcutaneous injection of DMH (purchased from Aldrich) at a dose of $12 \mathrm{mg} / \mathrm{kg}$ body weight in $0.9 \%$ sodium chloride, $\mathrm{pH} 6.5$ for 8 weeks according to an established protocol for inducing rat colon cancer ${ }^{[12]}$.

Group C received a weekly subcutaneous injection of $\mathrm{DMH}$ at a dose of $12 \mathrm{mg} / \mathrm{kg}$ body weight in 0.9 $\%$ sodium chloride, $\mathrm{pH} 6.5$ for 8 weeks and at the same time the rats were switched to the diet supplemented with 500 p.p.m. aspirin based on the previous report ${ }^{[13]}$. 
3- Aberrant Crypt Foci Assay:

Rats were sacrificed after 8-weeks and the colons were removed and flushed with cold phosphate buffer saline (PBS) and then cut open along the longitudinal median and fixed flat in $10 \%$ buffered formalin for $24 \mathrm{~h}$. The method of Bird ${ }^{[14]}$ was used to stain and highlight ACF. For each test agent, the number of ACF was evaluated in the $0.3 \%$ methylene bluestained colon by a specialist. We scored ACF under X40 magnification.

Colon specimens were processed as formalin-fixed and paraffinembedded tissues sections. Five $\mu \mathrm{m}$ thick slide-mounted sections were submitted for routine $\mathrm{H} \& \mathrm{E}$ staining for histopathological examination according to Sunter et al. ${ }^{[15]}$. According to the histopathological pattern, ACF were classified as nonhyperplastic, hyperplastic and dysplastic type ${ }^{[16]}$.

4- Immunohistochemistry Study:

For immunohistochemistry $5-\mu \mathrm{M}$ thickness were cut from the paraffin blocks. The section were deparaffinized with xylene and rehydrated with ethanol. Non enzymatic antigen retrieval was performed in each slide and washed with PBS. Then incubated with primary antibodies for survivin and COX-2 (Lab Vision Co.). Positive signals were detected using Lab Vision Universal Detection Kit according to manufacture protocol.

\section{5- Immunoblotting:}

Another part of colon from different groups was homogenized in RIPA buffer containing protease inhibitor cocktail. Samples were centrifuged at $10000 \mathrm{~g}$ for 15 minutes and the total protein content of the supernatant was determined.

Thirty $\mu \mathrm{g}$ of total protein were applied then evacuated with gentle application of vacuum using the Slot Blot Filtration Manifold (Hoefer Scientific Instruments, USA). The membrane was incubated in blocking solution PBS pH 7.2 containing $5 \%$ non-fat milk. The membrane then probed with the primary antibodies; anti-COX-2 (1:100) (Lab Vision Co.) and anti-survivin (1:200) (Santa Cruz Biotechnology).

Then the membrane was incubated with secondary antibody (horseradish peroxidase-conjugated goat antimouse) and the color was developed using DAB (3, 3 aminobenzidine tetrahydrochloride). The band density is measured by Scion Image Computer Program.

6- Statistical analysis

The data was statistically analyzed using computer database (SPSS program, Version 13). Data comparisons were performed by using two tailed unpaired student t-test and the correlation between the biochemical parameters were performed using Pearson's correlation coefficient. $\mathrm{P}$ value below 0.05 was considered significant.

\section{RESULTS}

The ACF assay:

The selected part of the colon was embedded, sectioned and stained. The slides were examined for the presence of ACF (Fig.1) that indicates a premalignant lesion induced by the carcinogen $(\mathrm{DMH})$.

Ten specimen for each group were examined in total 30 specimens been 
examined. Rats that were treated with saline showed no evidence of ACF formation while in DMH-treated rats it was around $82.6+3.1$ and after aspirin administration it was reduced to $34.9 \pm 4.5$ ( $\mathrm{p}$ value $=0.0001)$. In $\mathrm{DMH}$ treated group about $53.2 \%$ of AFC were showing the criteria of dysplastic lesion in the form of elevated surface of their mucosa, hematoxylin and eosin stains display the marked nuclear atypia, loss of cell polarity, and increase in mitoses consistent with high-grade dysplasia. After aspirin treatment the percentage has been greatly reduced to $21.7 \%$ showing a $59 \%$ reduction in dysplastic lesions of total AFC.

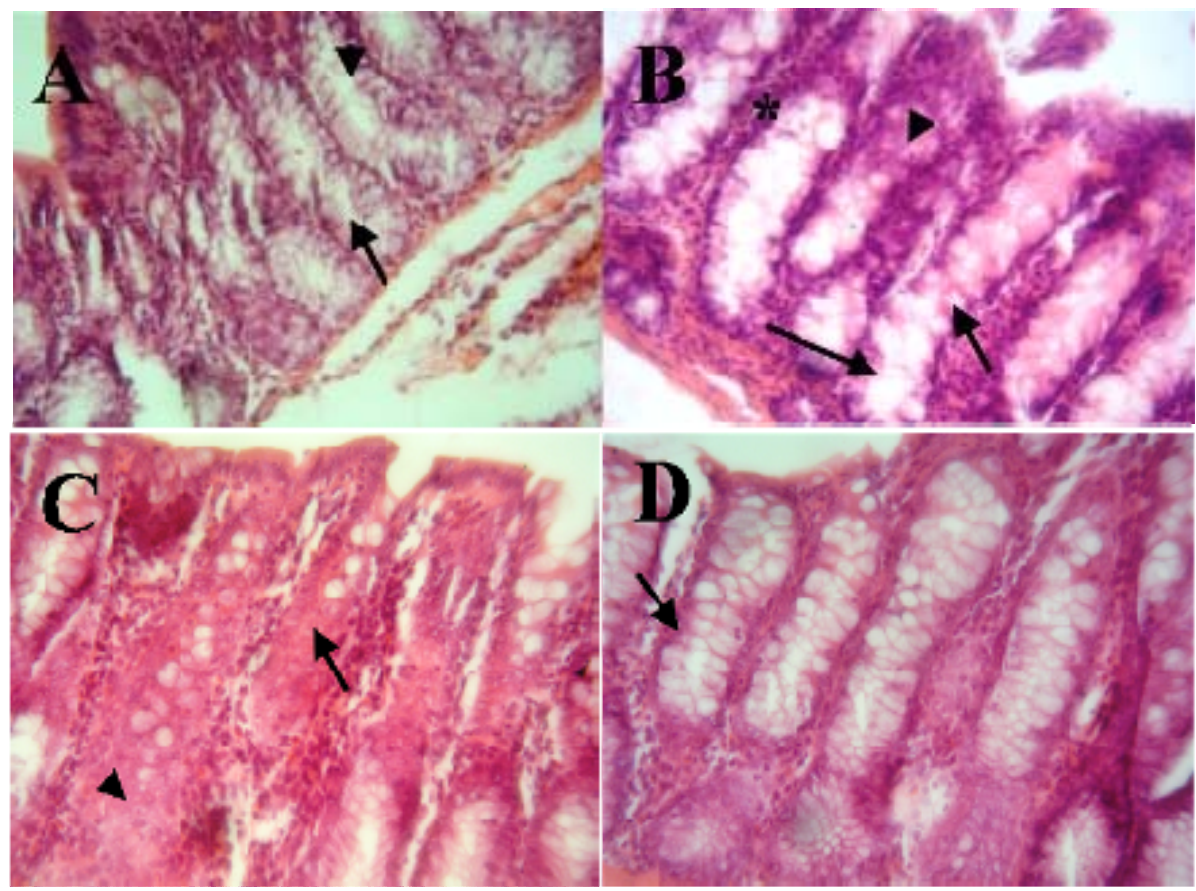

(Fig. 1): Photomicrograph of mucosa of the colon stained with H\&E (x400) showing (A) Normal appearance of the intestinal glands (arrow) with large number of goblet cells (arrowhead). (B) Mucosa of the colon after DMH administration. Abberant crypt foci with hyperplasia (arrow) mucin depletion (arrowhead). Notice the dark stained nuclei of malignant cells (asterisks). (C) Mucosa of the colon after DMH administration showing dysplastic AFC with complete obliteration of the lumen (arrow) areas of necrosis could be also observed (arrowhead). (D) Intestinal mucosa after treatment with DMH and aspirin at the same time only hyperplasia of ACF could be observed no dysphasia, notice the decrease in the population of darkly stained nuclei of malignant 


\section{Survivin and COX-2 expression}

We evaluated the modifications in the expression of survivin and COX-2 in the early stage of colorectal carcinoma and the effect of aspirin on those markers. By IHC we found that survivin was not expressed in normal colorectal mucosa (Fig 2A) while the expression of survivin was observed in the cytoplasm of ACF with relative increase in the dysplastic type and even in the apparently normal mucosa after DMH administration (Fig. 2B) suggesting that the expression of survivin is an essential event in the early stage of colorectal carcinogenesis. Also, we found that aspirin was able to decrease survivin expression indicating the possible role for survivin in the development of aspirin-induced apoptosis (Fig. 2C).

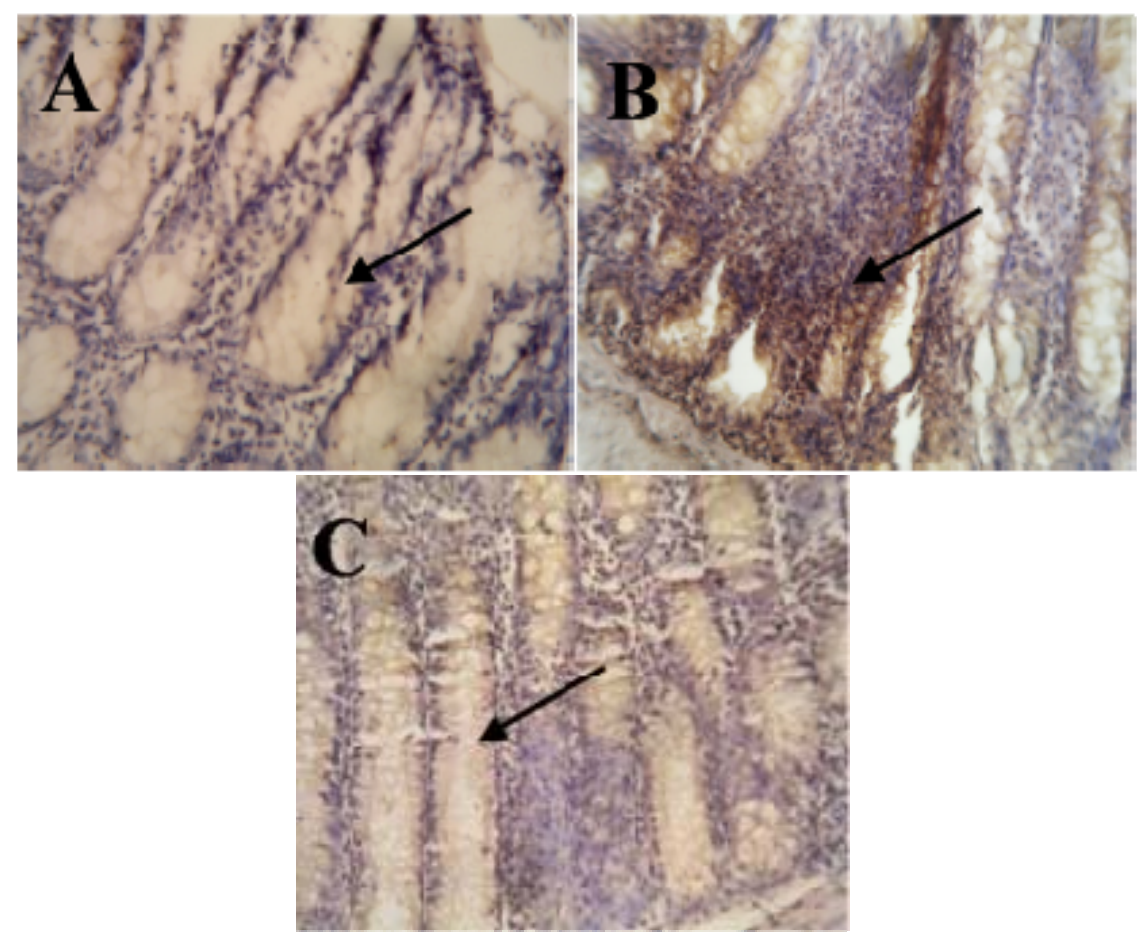

(Fig.2): Photomicrograph of mucosa of the colon showing immunohistochemical expression of survivin (A) absence of survivin expression from the normal intestinal mucosa (arrow) (B) Mucosa of the colon after DMH administration showing marked upregulation of survivin expression in AFC (arrow) (C) Intestinal mucosa after treatment with DMH and aspirin at the same time. Notice downregulation of survivin expression in ACF (arrow). X400. 
Also, these results were confirmed by imuunoblotting. The results indicate a highly significant increase ( $\mathrm{P}$ value $<0.001)$ in the survivin expression in rats' colon injected with $\mathrm{DMH}$ and it was found that acetylsalicylic acid (ASA) treatment significantly reduced the levels of survivin ( $\mathrm{P}$ value $<0.001)$ (Fig 3). These results suggest that the anticancerous effect of ASA on the early stages of colorectal carcinoma might be due, at least in part, to the observed reduction in survivin protein levels.

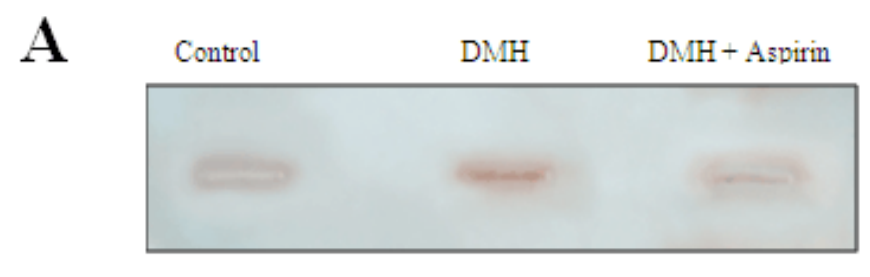

B

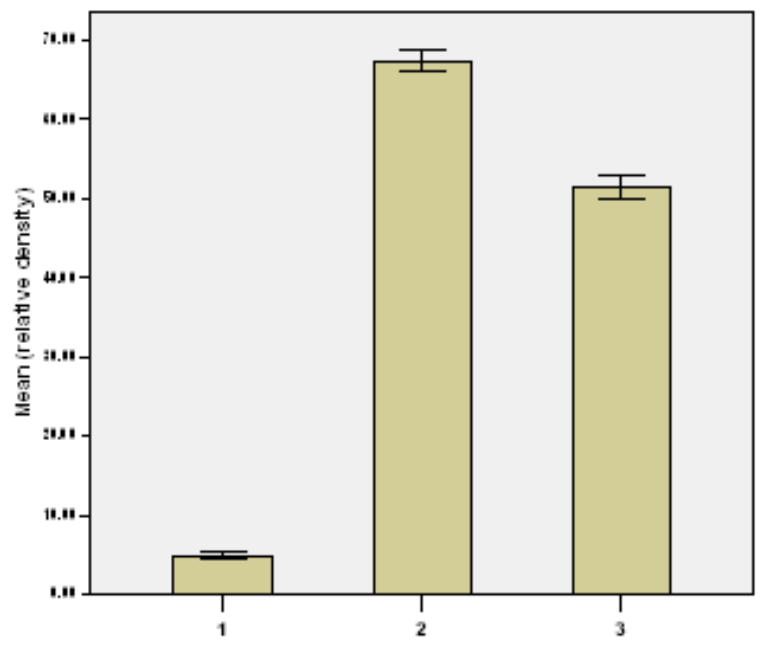

(Fig 3): Effect of aspirin on expression of survivin in induced ACF in rats. (A) Represents the expression of survivin in different groups of the study. Equal amount of protein were applied in slot blot and immunoblotted with anti-survivin. (B) Represents mean of relative density of densitometry of survivin in slot blot (1: normal group,2: DMH group,3: DMH and aspirin treated-group). 
OX-2 expression was also examined by immunohistochemistry (IHC). There was low expression of COX-2 in the cytoplasm of normal colon (Fig. 4A) while it was highly expressed in ACF (Fig. 4B) indicating that $\mathrm{COX}-2$ over-expression is an early event during colon tumorigenesis. After treatment with aspirin it was observed that there is downregulation in the expression of COX-2 (Fig. 4C) suggesting that COX-2 plays an important role in the development of colorectal cancer and anti-cancerous effect of aspirin is attributable to their ability to inhibit COX-2 overexpression.

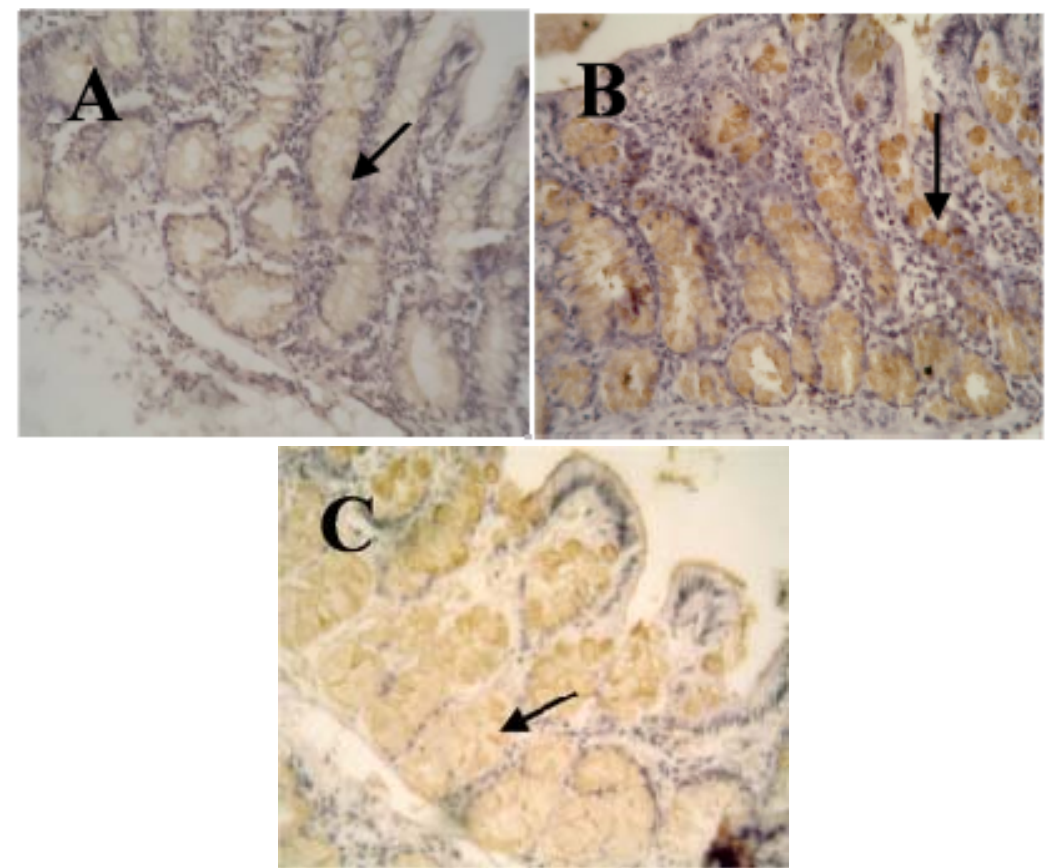

(Fig.4). Photomicrograph of mucosa of the colon Showing immunohistochemical expression of COX-2 (A) low expression of COX-2 expression from the normal intestinal mucosa (arrow) (B) mucosa of the colon after DMH administration showing marked upregulation of COX-2 expression in AFC (arrow) (C) intestinal mucosa after treatment with $\mathrm{DMH}$ and aspirin at the same time. Notice downregulation of COX2 expression in ACF (arrow). X400

Consistent with IHC, slot blot indicated a marked increase in COX-2 expression in ACF compared with control group ( $\mathrm{P}$ value $<0.001)$ and administration of aspirin with the carcinogen has significant reduction in the expression of COX-2 compared to DMH group (P value < 0.001) (Fig.5). 
A

Control

DMH

Aspirin - DMH

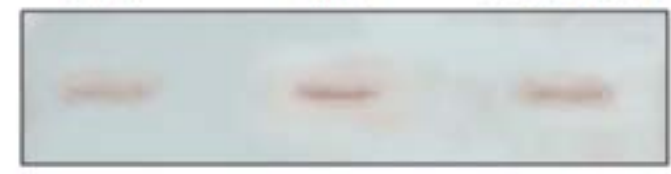

B

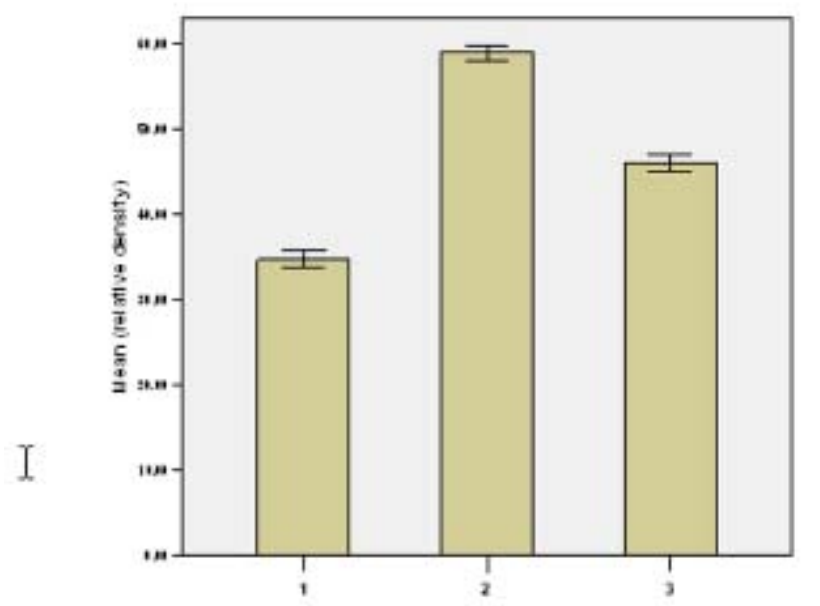

(Fig 5): Effect of aspirin on expression of COX-2 in induced ACF in rats. (A) Represents the expression of COX-2 in different groups of the study. Equal amount of protein were applied in slot blot and immunoblotted with anti-COX-2. (B) Represents mean of relative density of densitometry of COX-2 in slot blot (1: normal group, 2: DMH group, 3: DMH and aspirin-treated group).

\section{3-Correlation:}

We found that there is a significant positive correlation between survivin and COX-2 expression both in group treated with $\mathrm{DMH}$ and aspirin-treated group $(\mathrm{r}=0.816$ and $\mathrm{r}=0.742$ respectively), (Fig. 6 \& 7) suggesting that these proteins may have common pathway or affect each other during early stages of colorectal carcinoma. 


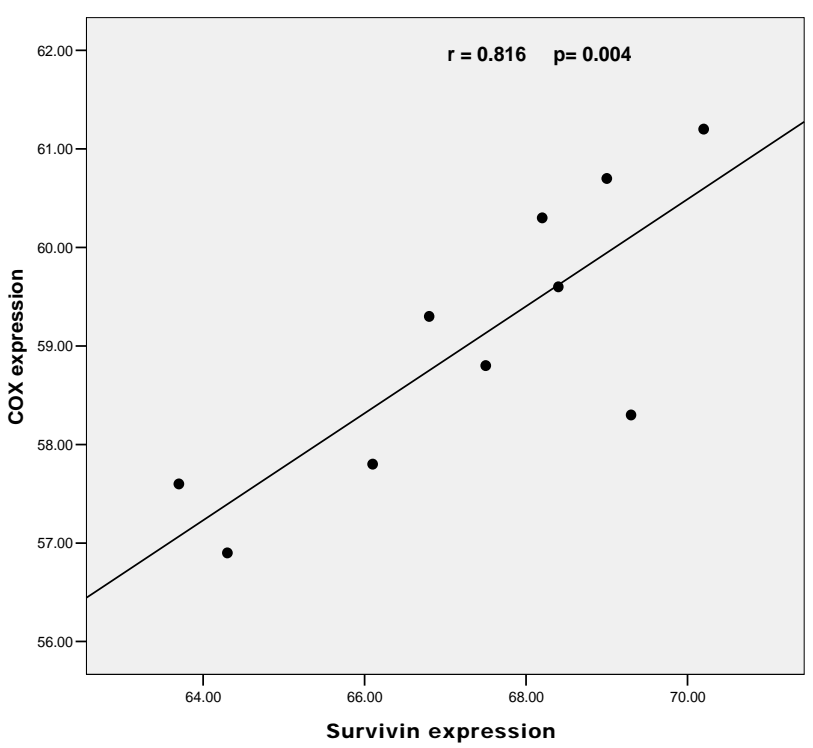

(Fig. 6): Correlation between survivin and COX-2 expression in DMH-treated animals (group B)

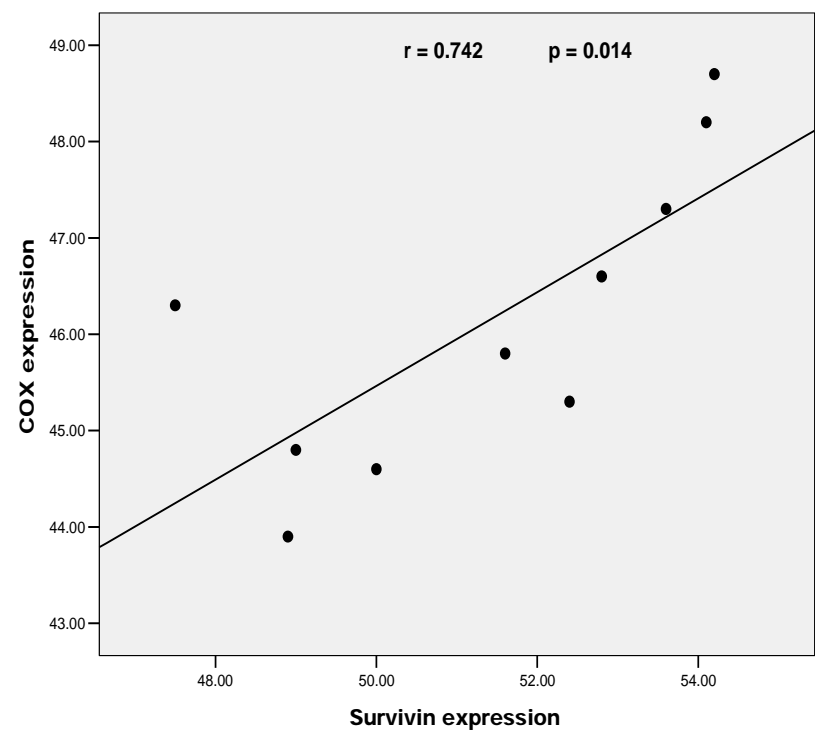

(Fig.7): Correlation between survivin and COX-2 expression in $\mathrm{DMH}+$ aspirintreated animals (group C) 


\section{DISCUSSION}

Colorectal cancer is a significant cause of mortality, however up to 80 $\%$ of sporadic colorectal tumors are considered preventable so the methods of colorectal cancer prevention are therefore of considerable importance ${ }^{[17]}$.

The understanding of the development of colon cancer has progressed rapidly over the past decades, and it is now well established that most colorectal cancer develops from neoplastic precursor lesion ${ }^{[18]}$. The subgroup of people with adenoma offers an excellent opportunity for specific chemoprevention with various agents, such as non-steroidal anti-inflammatory drugs (NSAID).

In the present study DMH administration for 8 weeks successfully induced aberrant crypt foci (ACF) which are putative preneoplastic lesion that are believed to be precursors of colorectal carcinoma in rats and possibly in humans ${ }^{[19]}$. We found that aspirin administration with DMH significantly displayed a $59 \%$ reduction in dysplastic ACF which are truly neoplastic microscopic lesions and have been recognized as the most important lesions in the ACFadenoma-carcinoma sequence. That finding confirms the data of Shpitz et al. $^{[20]}$ who showed that aspirin- treated patients displayed a reduced proportion of dysplastic ACF from $13.3 \%$ in the positive control group to $6.3 \%$ in aspirin treated group.

For better understanding of the mechanism through which aspirin can exert its chemopreventive effects in the colorectal carcinoma we studied the effect of aspirin on the expression of COX-2 and survivin.

Lian et al. ${ }^{[21]}$ reported that survivin expression is an essential event in the early stages of human colorectal carcinogenesis; this is in accordance with our results which showed complete absence of survivin from normal mucosa and its appearance even in the apparently normal mucosa after DMH administration. In cancer cells, elevated survivin is commonly associated with enhanced proliferative index, reduced levels of apoptosis, resistance to chemotherapy and increased rate of tumor recurrence ${ }^{[11]}$ making antisurvivin therapy an attractive cancer treatment strategy.

In previous study it was observed that ASA does not affect survivin mRNA levels in breast cancer cells suggesting that ASA acts by a posttranscriptional proteasomedependent mechanism to reduce survivin protein levels ${ }^{[22]}$. Our study worked on protein level as through IHC and immunoblot we found that ASA treatment significantly reduced the levels of survivin indicating that aspirin may exert its chemoprotective effect partially through antagonizing the antiapoptotic effect of survivin protein.

Several preclinical studies have shown that disrupting survivin expression or function in cancer cells decreases their proliferation and enhances apoptosis ${ }^{[11]}$. Also, Yoo and Lee $^{[4]}$ observed that ASA treatment resulted in a significant decrease in the level of survivin among IAP family in prostate cancer cells.

Recent data suggest that COX-2 is involved in the process of malignant 
transformation and tumor progression. COX-2 seems to be involved in the development of colorectal cancer according to genetic and pharmacological evidence ${ }^{[23]}$. It was reported that $\mathrm{COX}-2$ over-expression is important during colorectal carcinoma; however it is unclear exactly where in the multistep process COX-2 deregulation occurs ${ }^{[18]}$. In the current study, it was found that there is a marked increase in COX-2 expression in ACF compared with control group demonstrating that COX-2 over-expression is an early event during colon tumorigenesis.

In a recent study, it was observed that use of aspirin after a diagnosis of non-metastatic colorectal cancer was associated with a decreased risk of colorectal cancer-specific mortality. This inverse association appeared to be strongest among participants whose primary tumors over-expressed COX$2^{[3]}$. Our results are consistent with these findings as we found that ASA significantly reduce the expression of COX-2 which is of great benefit as over-expression of COX-2 in tumor tissue has been associated with a poorer prognosis among colorectal cancer patients in some studies ${ }^{[24,25]}$.

Correlation between COX-2 and survivin had been described in the study of Erkanli et al. [26] who reported that COX-2 and survivin might share a common molecular pathway or enhance each others actions in the developmental pathway of endometrial carcinoma. Younis et al. ${ }^{[27]}$ showed the same observation in male breast carcinoma as they described the correlation between COX-2, survivin and intratumoral aromatse, and they mentioned that such correlation may have therapeutic implication in the treatment of male and female cancer breast.

To our knowledge it is the first time to describe the correlation between COX-2 and survivin in induced colorectal carcinoma. This correlation appears in DMH-induced aberrant crypt foci and after aspirin treatment. Such correlation between these two proteins should be further investigated to assess potential chemopreventive opportunities for combining COX-2 and survivin inhibitors.

Taken together, we have shown that survivin and COX-2 are overexpressed and positively correlated in early stage of colorectal carcinoma and aspirin can exert a significant effect as a chemoprophylactic agent through downregualtion of these two proteins. So, we think that targeted therapies against survivin and COX-2 may be valuable in chemoprevention and treatment of colorectal carcinoma.

\section{REFERENCES}

1. Grady WM and Markowitz. SD (2002). Genetic and epigenetic alterations in colon cancer. Annu. Rev. Genomics Hum. Genetics 3: 101- 128.

2. Cheng L and Lai MD (2003). Aberrant crypt foci as microscopic precursors of colorectal cancer. World J. Gastroenterology 9 (12): 26422649.

3. Chan AT, Ogino $S$ and Fuchs CS (2009). Aspirin use and survival after diagnosis of 
colorectal cancer. JAMA; 302 (6): 649-658)

4. Yoo $J$ and Lee YJ (2007). Aspirin enhances tumor necrosis factor-related apoptosis-inducing ligand-mediated apoptosis in hormone-refractory prostate cancer cells through survivin down-regulation. Mol. Pharmacol., 72: 1586-1592.

5. Dong M, Guda K, Nambiar PR, Rezaie A, Belinsky GS, Lambeau G, Giardina $C$ and Rosenberg DW (2003). Inverse association between phospholipase $\mathrm{A}_{2}$ and $\mathrm{COX}-2$ expression during mouse colon tumorigenesis. Carcinogenesis 24 (2): 307-315.

6. Rodriguez DA, Tapia JC, Fernandez JG, Torres VA, Munoz N, Galleguillos D, Leyton L, and Quest AF (2009). caveolin-1-mediated suppression of cyclooxygenase-2 via a Bcatenin-Tcf/Lef-dependent

transcriptional mechanism reduced prostaglandin $\mathrm{E}_{2}$ production and survivin expression. Mol. Biol. of the cell 20: 2297-2310.

7. Ambrosini G, Aidida $\mathrm{C}$ and Altieri DC (1997). A novel antiapoptotic gene, surviving expressed in cancer and lymphoma. Nat. Med., 3: 917921.

8. Salveen GS and Duckett CS (2002). IAP proteins: blocking the road to death's door. Nat. Rev. Mol. Cell. Biol., 3: 401-410.

9. Li. F, Yang J, Ramnath N, Javle MM. and Tan D (2005). Nuclear or cytoplasmic expression of survivin: what is the significance? Int. J. Cancer 114(4): 509-512.

10. Altieri DC (2003). Survivin, versatile modulation of cell division and apoptosis in cancer. Oncogene 22:8581-9.

11. Fukuda $S$ and Pelus LM (2006). Survivin, a cancer target with an emerging role in normal adult tissues. Mol. Cancer Ther., 5(5):1087-1098.

12. Cameron IL, Ord VA, Hunter KE and Heitman DW (1990). Colon carcinogenesis modulation of progression. In colon cancer cells, Moyer MP and Poste G (eds), pp. 63-84. Academic press: Orlando

13. Reddy BS, Rao CV, Rivenson A and Kelloff $G$ (1993). Inhibitory effect of aspirin on azoxymethane-induced colon carcinogenesis in F344 rats. Carcinogenesis 14 (8): 1493-7.

14. Bird, RP (1987). Observation and quantification of aberrant crypts in the murine colon treated with a colon carcinogen: preliminary findings. Cancer Letter 37: 147-151.

15. Sunter JP, Appleton DR, Wright NA and Watson AJ (1978). Pathological features of the colonic tumors induced in rats by the administration of 1,2 dimethylhydrazine. Virchows Archiv B, cell patho., 29:211223.

16. Di Gregorio C, Losi L, Fante R, Modica S, Ghidoni M, Pedroni M, Tamassia MG, Gafa L, Ponz de Leon $M$ and Roncucci $L$ (1997). Histology of aberrant crypt foci in the human colon. Histopathology 30: 328-334. 
17. Chell S, Kadi A, Williams AC and Paraskeva C (2006). Mediators of $\mathrm{PGE}_{2}$ synthesis and signaling downstream of COX-2 represent potential targets for the prevention/treatment of colorectal cancer. Biochim Biophys Acta., 1766 (1):104-19.

18. Sangha $S$, Yao $M$ and Wolf MM (2005). Non-steroidal antiinflammatory drugs and colorectal prevention. Postgrad. Med. J., 81: 223-227.

19. McLellan EA, Medline A and Bird RP (1991). Dose response and proliferative characteristics of aberrant crypt foci: putative preneoplastic lesions in rat colon. Carcinogenesis 12: 2093-2098.

20. Shpitz B, Klein E, Buklan G, Neufeld D, Nissan A, Freund HR, Grankin $M$ and Bernheim J (2003). Suppressive effect of aspirin on aberrant crypt foci in patients with colorectal cancer. Gut 52: 1598-1601.

21. Lian LJ, Zheng CQ, Jin Y, Ma Y, Jiang WG and Ma T (2003). Expression of survivin protein in human colorectal carcinogenesis. World J. Gastroenterol., 9(5):974977.

22. Lu M, Strohecker A, Chen F, Kwan T, Bosman J, Jordan VC and Cryns VL (2008). Aspirin Sensitizes Cancer Cells to TRAIL Induced Apoptosis by Reducing Survivin Levels. Clin. Cancer Res., 14(10): 3168-3176.
23. Tong BJ, Tan J, Tajeda L, Das SK, Chapman JA, DuBois RN, and Dey SK (2000). Heightened expression of cyclooxygenase-2 and peroxisome proliferatoractivated receptor-delta in human endometrial adenocarcinoma. Neoplasia 2(6): 483-90.

24. Soumaoro LT, Uetake H, Higuchi T, Takagi Y, Enomoto M, Sugihara K. (2004). Cyclooxygenase-2 expression: a significant prognostic indicator for patients with colorectal cancer. Clin Cancer Res., 10(24): 8465-8471.

25. Uchida K, Schneider S, Yochim JM et al. (2005). Intratumoral COX-2 gene expression is a predictive factor for colorectal cancer response to fluoropyrimidine based chemotherapy. Clin. Cancer Res., 11 (9):3363-3368.

26. Erkanli S, Bolat F, Kayaselcuk F, Demirhan B and Kuscu E (2007). COX-2 and survivin are overexpressed and positively correlated in endometrial carcinoma. Gynecol. Oncol., 104(2):320-325.

27. Younis T, Hache' KD, Rayson D, Dewar R, Gray S, Barnes PJ (2009). Survivin and COX-2 expression in male breast carcinoma. The Breast 18: 228232. 


\section{تأثير الأسبرين على بروتين السيرفيفين و الكوكس-r وعلاقتهما بالمراحل البدائية لسرطان القولون

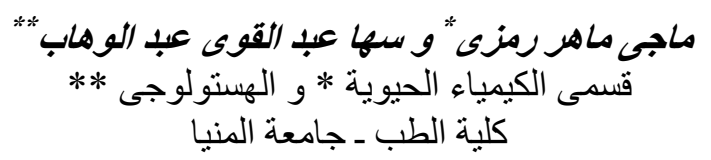

المقصود بسرطان القولون هو السرطان الذى ينشأ فى القولون و المستقيم وهو يمثل السرطان الر ابع الأكثر

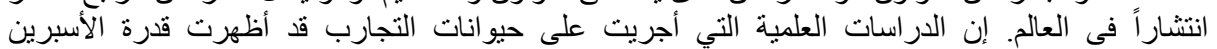

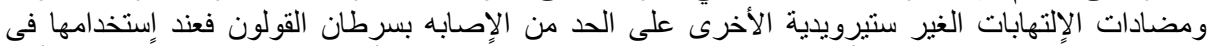

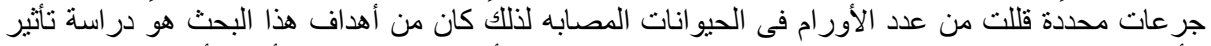

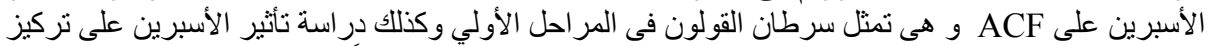

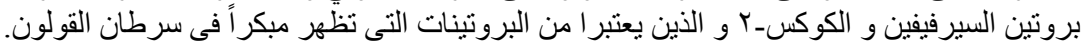

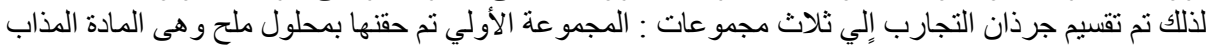

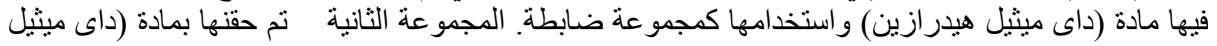

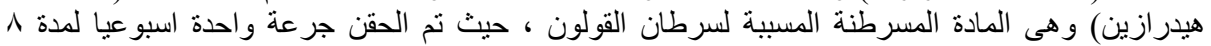

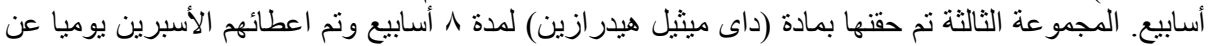

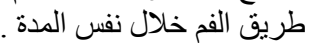

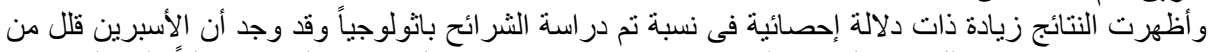

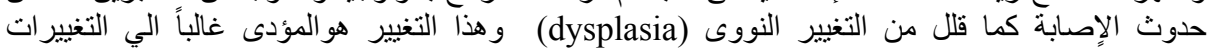

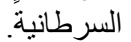

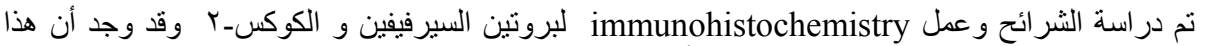

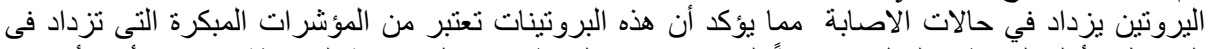

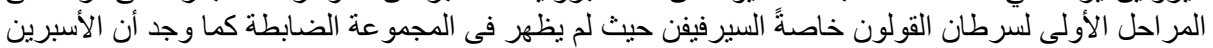

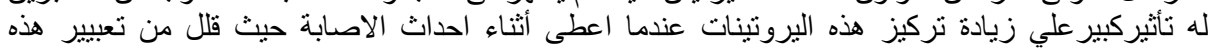

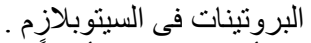

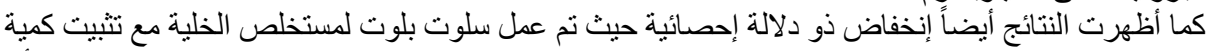

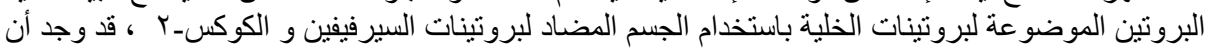

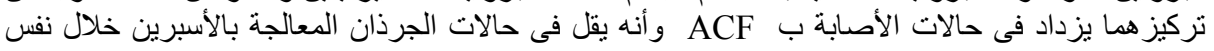

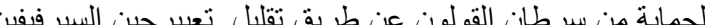
وبهذا قد وجد أن الاسبرين له القدرة على الحماية من سرطان الفولون عن طريق نفليل نعبيرجين السيرفيفين

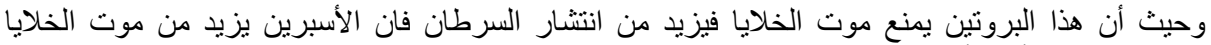

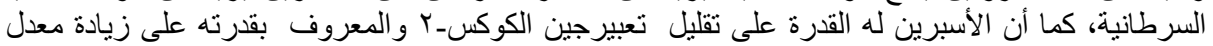

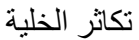

ان قدرة الأسبرين على الحماية من سرطان القولون خاصة فى مر احله الأولى مؤشر جيد لإستخدامه كو اقى من

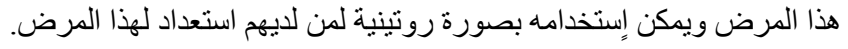

